\title{
Social Impact Assessment under RFCTLARR Act 2013 and Social Costs - An Analysis
}

\author{
Puranjoy Ghosh* and Abhishek Ray ${ }^{\dagger}$
}

\begin{abstract}
Mass-scale development, in the backdrop of increasing population, has appreciated the market-value of 'land' the important determinant that either directly or distantly affects the objectives of sustainable development initiatives. To ensure peoples' participation in such governance of developmental programs and satisfy the expansion of economic aspiration, significant changes have been brought in the normative frameworks of landacquisition, for example, streamlining of compensation policy (economic), integration of SIA and R\&R scheme (physical \& socio-cultural), involvement of affected persons within the fold of decision-making process (minimization of adverse effects particularly political disruptions), in the RFCTLARR, 2013. This space is used to explicate some popular economic indicators in the context of 'social cost' in RFCTLARR, 2013.
\end{abstract}

Keywords: RFCTLARR and Sustainability, Economic Growth, Peoples Participation

\section{Introduction}

Ownership of land has always denoted the hierarchy of power structures and social stratifications in the human civilization. In early centuries, the power-wielders often exercised rules of governance that had the overtone of authority as well as the pith

\footnotetext{
${ }^{*}$ KIIT(Deemed to be University), Odisha, India; puranjoy1@gmail.com

† KIIT (Deemed to be University), Odisha, India; abhishek.ray.90@gmail.com
} 
and substance of laissez-faire to fortify the succeeding capitalism. Therefore, implementation of the normative policy of such authoritarian regimes has been mostly unfair, uncertain and sometimes unfairly prejudiced. With the age of industrialization succeeded by the progression of free trade, mercantile capitalists evolved who transfigured their economic potentials to colonize the disintegrated and weaker pluralist political authorities and to secure the political dominance. Thus, colonization had gradually eventuated mercantile capitalism. The intrusion of expropriating predisposition of such overseas merchants adopted and institutionalized in the regulatory approach - the outcomes of which were predominantly cost-reduction for the overseas merchants with a greater focus on the generation of revenue. The normative rules of social relations as mostly viewed and structured by members of the dominating economic institutions ultimately succeeded at benefitting the mercantile capitalists and was repressive. Influence of Human Rights Movements, particularly, those after the Second World War warranted the proclivity towards decolonization and after the achievement of Independence most of the newly recognized sovereign states in global landscape desired to transform the governance mechanism within the democratic framework almost in all quarters of their social institutions and India is no exception of it. After independence, India prioritized the upholding of peoples' rights in the regulatory mechanism, command-control economic policy, etc. Necessary amendments upon the existing laws as well as new social legislation were initiated. State Capitalism and social welfare policy succeeded in India as well. However, prioritizing the socialistic economic order using a mixed economy system sustained the aspiration of the contributory role of private capitals to the economic growth of the country with special emphasis on state intervention within the normative framework. The transition of economic policy in the post-1990 period, i.e., from 'command-control' regulatory model to 'liberalized economy' model reorganized and reintegrated the official mission of 'Liberalization' in its legal frameworks. One of such progressive reform is the land rights of the peasantry in the event of land acquisition. RFCTLARR Act, 2013 is one such commendable step after six and a half decades of independence. 
The catalogues of interests designed to provide the landholders, in case of acquisition of private land for public use in RFCTLARR Act, 2013 is but the emendation of constitutional standards in the statute and the pre-eminent economic interests of the internally displaced persons is made visible. However, there is a divide between the prescriptive norms of monetary compensation and the context of decision-making relating to the economic and non-economic loss or injury of the internally displaced persons on such land-acquisition. The substantive implications of Land Acquisition are but the transfer of the invaluable property rights, i.e., the natural resources along with the right to control from one person to other. In such a transaction of sales, the decisive factor is the monetary consideration mutually and voluntarily accepted between the buyers and sellers. The companionship of different functionaries within the procedural framework of such acquisition process has been ensured, regarding them as 'trustees' of the underprivileged or disadvantaged sellers. The pertinent issue is that often such process of resettlement and compensation negotiations settlement between the landowner(s) and 'Requiring Body', the grievances of the aggrieved being shadowed by dint of invasive economic judgments by some local political actors materialise the elbow room procured by virtue of the legislative frameworks. Such an eventual outcome of disparate treatments often forces the landowners to make his/her way above 'public purpose'. Acquisition of land for 'public purposes' follows the intervention of a limited class of people for the private interests of the affected members of the locality and inequalities of socio-economic conditions of all such internally displaced. Social Impact Assessment Unit furnishes the report applying the doctrine of $s u b$ - silent $i$ without taking the degree of care for evaluating the losses or injuries caused to marginal members of that land-ouster. The inequalities have often been perceived even among the land-ouster during settlement process when properties to be acquired are similarly situated but being the owner of smallholding lowball offers are made while socio-cultural values play special significance to such socially and economically underprivileged. What has been included by the legislature in the present Acquisition Act is the possible economic earnings within the purview of the compensation mechanism. However, the extent and amount of the net value of incidental benefits and 
quantification of the loss to be caused due to deprivation of the socio-economic and cultural values of such development program, has not been underlined for such socially, psychologically and physically affected Internally Displaced Persons (IDPs). This aspect as mentioned above has been itemized as one indicator to be taken note of in the Social Impact Assessment although eventual outcomes on such points is subject to the Government only, i.e., the rule of sub-silent. Recognition of such loss is considered if the possibility of affecting the 'demographic dividend' is perceived by such political actors to a larger scale. Prioritizing the interests of the larger scale reveals the undermining role and relationships between the rulers and IDPs in such a changing context of sustainable development. The marginally-affected ouster always prefers to account it from the perspective of an individual's loss.

To overpower the legislative and to ensure the prudence of absolute necessaries of life are considered as superfluous enjoyment in a political journey. As mentioned above, the implementing practices in providing the opportunities to the public representativesii in settlement process conducted through the public hearing, often conceived to serve greater interests are sufficient rooms for political actors to underwrite the 'free consent' of proposed land-ouster, initially by way of inducement and at time by threats to proclaim the success of political agendaii in such development mission.

Per contra, where the political ideologies are different between the local leading political agencies of the local authorities and the State or where consensus is different between those who are in the governance apparatus of the State and those at the local authorities' things appear to be worse. The context appears dicey if the majority of such aggrieved land-ousters belong to opposite political ideologies. To defeat the voice of grievances of marginal numbers, often the dominant political parties in 'public hearing process' abuse process to assemble politically motivated majority voice to procure suitability of the developmental model. Therefore, the jurimetrics outlined in the legal landscape of the RFLARR Act, 2013 to ensure the concurrent developmental programs has given piecemeal attention relating to warrant the significant dynamics for the deprivation of socio-cultural values in such acquisition 
programs. The settlement through bargaining inland acquisition is completely an out of court process but the intervention of some politically affiliated intermediaries in it asks for potential remedies for it. The communicative practices and approach to the matters of procedures relating to Social Impact Assessment in case of land acquisition for the purpose of "better use" and economic development are prescribed to be the considered by the Government. For example, the autonomy of mode of use and the development of their property by such private owners (Kelo v. City of New London, 2005) has been underrated in comparison to the 'public purpose' in case of PPP model of developmental programs. The compensatory package quantified for each such land-ouster contains, inter alia, the socio-cultural dimensions. However, the injuries for the loss of socio-cultural values hardly been quantified. The Rehabilitation and Resettlement mechanism would facilitate the relocation but hardly any implication is in the Act for reintegration. Social cost should be borne by such land-ouster at newly settled locations to develop the cooperative neighbourhood. Even with the varied distribution in the decision-making process in ascertaining such loss of socio-cultural values is provided by SIA, the ultimate decision maker to evaluate the loss is the State. Encouragement of impartial quantification in such loss of sociocultural values at different layers of the decision-making process by the prospective land-ouster vis-à-vis the intensity of investment by prospective investors enlarges the opportunities to concoct 'economic rents' to some intermediaries. They ensure their presence in such 'public hearing' and settlement process. Freedom to walk away from giving consent in favour of the acquisition process is provided to every individual but the intervention by political actors in maturing the ground of 'public interests' among the general public and socio-political condemnation against such marginal individuals have not yet been addressed.

The reforms brought forth in the Land Acquisition in India through amendments for the effective and efficient policy implementation introduced the political transaction costs and designed the legal frameworks. Thus surfaced the dilemma in making choices between market and human rights in the operative principles for sustainable developmental programs. The pursuit of sustainable development programs spurred scales of economic benefits which 
resulted in diverse pursuits of livelihood that emulated multidimensional economic opportunities of earnings and expenses. Considering the diversity of socio-economic status of the holders at the micro-levels, the attribution of values by each land-ouster with respect to the holding so acquired is bound to be distinct when compared to the rules of justice and reasons as concluded by the legislature at macro or meso-level. Global economic parlance appreciates the appraisal of time-bound, skillful and efficient working forces in any organized economic activities. Most of the time, the land-ouster being unskilled, illiterate working forces, there is a potential impediment in accommodating most of the land-ouster in the permanent payroll of the proposed development programs rather they are being absorbed on screening mostly in schematic temporal enrollment. It ends with the completion of the project ready to run - the outcomes that frustrate the social-welfare measures of the Activ. The social welfare measures framed in the rehabilitation scheme in the Act of 2013 has not emphasized any transactional arrangement that can minimally be marked as proportionate to the deprecation of socio-cultural values at the micro-levels.

The social determinants in relation to 'land' that are having sustaining influences on the preferences and cognition, endogeneity, social interrelations, etc. in the boundaries of the locality or community reinforce few microeconomic aspects which are not traded in any market. Deprivation of these things of value has been asked to be accommodated in the Social Impact Assessment in order to compensate for the non-economic injuries of those internally displaced persons affected on land acquisition. 'Solatium' does not compensate equivalence of those values (Radin, 1993) and again it is retained to be used by the government on considering the Impact Assessment Report. The expression 'solatium' has accounted for the spread of the social costs that the IDPs are to incur overtime till the completion of relocation and rehabilitation schemes and reintegration to the newly allottedlocality on such acquisition. The incidental developmental benefits to the existing members of the locality would be equivalent to the compensatory packages provided to the IDPs of the same locality. They require attention to evaluate the robustness of the SIA mechanism in the Land Acquisition Act, 2013 considering the 32 
increasing trends of a price index. The inherent scarcity in the market in addition to increasing population and incremental modifications in the modes and manner of use has already characterized 'land' as a high-end object. Any sustainable development project in its SIA integrates the life-cycle dynamism, stakeholders' heterogeneity and social responsibility interactivity within its fold and counts above all the well-being of wider society. The phenomenal aspect in land acquisition for such purpose is rehabilitation and resettlement but no legislative prescription is made regarding the 'reintegration' within the fold of 'resettlement'. The question of reintegration of the IDPs in the newly allottedlocalities reflects the complexity of relations in repositioned host societies. It facilitates the role of 'government - non-profit relations' to support integration and collaboration process in resolving multilayers disparities due to such demographic shifts in such relocation. What is emphasized upon is the minimizing of adverse social impacts or risks due to such proposed developmental programs on the acquisition. The socio-cultural values viz. safety, cooperation, cultural ties, integrity in inter-personal bonding of the locality projected for the Requiring Body as well as the costs to be incurred initially to ensure the uncertainty, difference in morale, distrust, complexity, conflicts, safety to the relocated locality on each IDP. This is done with consideration to guide the SIA program which with regard to reintegration has been left to consensus of the ruling political in the administrative apparatus of the State. A designed deliberation against such proposition may be tailored under the 'larger interests' context however reasonably it may be contended with regard to the expression 'Fair Compensation' in the 'Title' of the Act. It relates to the subsequent disparities in enjoying economic benefits by such marginalized IDPs in the host locality. Fairness to majority may be called for but certainly not responded to with every IDP in such a progressive move of sustainable development mission. Complete indemnification to the owners for their losses and fair market value compensation of such land acquisition appears to be an economic supplement to a greater scale. However, the cost overtime being borne by such IDPs in new associations for evolving cooperative neighbourhood relations with the members of host societies essentially manifests to be an 
incidental part that entails the role and attitudes of the government agencies and the policymakers in such reintegration process ${ }^{v}$.

The expression 'public purpose' is wide enough to represent the larger interest of the society however the configuration of the expression in view of the sustainable developmental program appears to be multi-dimensional and mostly correlated to landacquisition. The compensatory package in the RRLARR, 2013 has not been designed from the perspective of cardinal utility and hence the SIA has not included the option of the difference of preferences to the land-ouster on the acquisition. Quantification of loss of land is being determined on the present market-price while the life-line of the project is accounted from the perspective of Value for Money approach. Therefore, the appreciation of values, benefits and opportunities of sustainable development and the IDPs to be enjoyed by the inhabitants of that proposed locality is quantified within the fold of 'solatium'. The option of different preferences between potential scopes of economies and choice for availing the compensation package is not enunciated to the landholders. rather the choice of withdrawal of consent is blocked. Question of influence or innocence or ignorance of business acumen regarding the microeconomic impact in the event of giving consent has not been framed in the legal framework. The external cost incurred by each individual land-ouster for reintegration process in host locality has not been warranted also.

Hollow-hearted influence is the perennial spring of all prodigality and of all disorders to the inmost fibre of the legal frameworks. Being credibly informed, the ruling political parties of the localities upon exhibiting the beneficent public spirit sneaks in to simplify the functions of the administration of the localities of proposed land acquisition. It is done so with the covert motive to ensure the extent of characterizing the arbitrary financial mechanism of a regular and methodical credit system within the proposed development project where they can ensure the 'economic rent' upon such proposed land acquisition of the marginal landholders. Of late, the economic growth has significantly emphasized upon the cooperative approach towards the private enterprises while managing the fiscal difficulties for public welfare and privatization, outsourcing and contracting out and the dominant PPP model. 
They are but the exposition of those behind the role as facilitator. This strategic public management enables the State to allocate the risk unto private entities and hence the private entities which can withstand such risks are often qualified for such sustainable developmental programs. Such structured fiscal policy is balanced by promoting private financing in the development program of the State. The political actors often extend political patronage to the prospective investors for sustained investment.

The multiplier effect of foreign investment on the economy of the country has encouraged promoting FDI mostly through PPP Project. What is to be substantial in the legal frameworks in a comprehensive manner is of equal importance to the deprivation of an individual's interests and the incidental benefits designated to the public interests that are scarcely structured. To arrest the attention of the prospective foreign investors, the institutionalization of liberalization of the economy, free trade, notable changes in the legal system and policies become the priorities. Such innovative developmental policies explicitly appreciate the business model approach. The importance is given to the long-term productive efficiency of the projects. This structural vehicle of investment or to say alternative privatization with modified legal frameworks embrace capital development agenda bearing the name of social welfare. The dynamics of contract-awarding and contractual arrangements do not provide even-distribution of powers and risk-allocations - resulting in possible changes in behavioural patterns. The development with a view to produce long-term efficient economic outcomes to be made on 'acquired' land appreciates the value. However, as stated above, the government accumulates the inherent natural advantages out of the inequitable distribution-dynamics reduced in the contract. This often leads the private actors to a circumvention of the implementation of welfare or compensatory mandate of resettlement and rehabilitation schemes in spirit. They rely upon the political patronage awarded the contract - creating thereby in equilibrium between the regulatory and substantive approach of the legislation. The microeconomics associated with the bundle of interests in property rights are accounted in view of MultiAttribute-Utility approach where the cardinal utility plays a vital role in determining the exercise of potential choice by the 
prospective foreign investor in such sustainable developmental program. Again, the conditional preferences and certainty through BIT sneak into such an arrangement. In short, the risk-return ratio, opportunity costs of capital, etc. are thoroughly been accounted at the formative stage of any such sustainable development project while nowhere has such options of preferences and remedies for the deprivation of socio-cultural values been appraised in RFLARR, 2013.

Apart from these, the stable political environments have also received considerable attention of such prospective foreign investors considering the risk-return ratio. Most Bilateral Investment Treaties are drawn on the consequential outcomes of what appear to be repressive to host countries. Differential treatment based on the principles of 'Proportional Equality' may compensate for the loss sustained by the aforesaid socially and economically marginalized IDPs, if underpinned in the SIA framework. The Social Impact Assessment mechanism concentrates upon the Social Return on such Investment for the developmental program and not for the Social Costs to be sustained by such marginalized IDPs. Conversion of unprofitable titles into a productive estate has to be prioritized otherwise there would wasting and incurring debts on the civil establishment of administration ultimately affecting national strength and national credit impracticable.

\section{References}

Radin, M. J. (1993). Compensation and commensurability. Duke Law Journal, 43, 53-69.

Kelo v. City of New London. Kelo v. City of New London, 125 S. Ct. 26552660 (2005).

i The SIA forwards the positive viability and sustainability report of the development project relying upon the 'Majority Rule' principle. For example, as in Rule 11 (4) of Odisha Right to Fair Compensation and Transparency in Land Acquisition, Rehabilitation and Resettlement Rules, 2016 the SIA Unit shall prepare the socio-economic and cultural profile of the affected area based on available data and statistics, field visits and consultations however, in the relocation scheme shall be 
prepared, apart from the affected members, representatives in the concerned local bodies - the perfect access point of the political actors in the rehabilitation and resettlement schematic process of the aggrieved.

ii Public representatives are none but the people affiliated to political vendetta and highly infused with opportunistic tendencies. For example, Rule 21(3) of Odisha Right to Fair Compensation and Transparency in Land Acquisition, Rehabilitation and Resettlement Rules, 2016 - notification two weeks in advance for the purpose of Obtaining Consent. Rule 6 categorically emphasized the prohibition of the scope of withdrawal of consent.

iii For example the Singur incident in West Bengal for the establishment of Tata Nano-car manufacturing unit.

iv Krushna Chandra Nayak v. The Railway Board \&Ors. 2014(II) ILR CUT - 290 - Brief account of this case is that the parcel of land acquired measuring to Ac. 14.08 decimals in the year 1999 (L.A.Case No. 5 of 1999) for the purpose of construction of Khurda Road-Bolangir New B.G. Rail Link Project by East Coast Railway - Prayer was to issue necessary appointment order in favour of the petitioner under Rehabilitation Assistance Scheme as against any substantive vacancy commensurate with his qualification as his family is in distress condition - the family was earning their livelihood out of usufructs from the acquired-property through agriculture - Rs. 78,292/- was granted as compensation by Land Acquisition Officer in the year 2001 No alternative plot allotted to his family - on query the Railway Authority informed that the employment to the family of the land oustees under Rehabilitation Assistance Scheme was under active consideration and necessary notification would be published once finalized - 2010 a scheme announced with the clause in deserving cases - Petitioner submitted application along with 'No Objection' from other family members - Railway authority without any response gone for fresh recruitment - Petitioner appeared before Central Administration Tribunal (O.A. No. 1032 of 2012) - CAT dismissed the O.A. in 2013 Petitioner filed Writ before H.C.

v For example, illegal demands like protection money, housing profiteering in the new localities etc. 